\title{
Health Empowerment of Older Adults with High-risk of Cardio-cerebrovascular Diseases
}

\author{
Son, HyoJin ${ }^{1} \cdot$ Kim, Gwang Suk ${ }^{2}$ \\ ${ }^{1}$ School of Nursing, University of Maryland, Baltimore, USA \\ ${ }^{2}$ College of Nursing · Mo-Im Kim Nursing Research Institute, Yonsei University, Seoul, Korea
}

Purpose: This study was to identify factors explaining health empowerment of older adults with high-risk of cardio-cerebrovascular diseases. Methods: Using a structured questionnaire, data were collected from 148 older adults residing in two areas who have one or more of the following diseases; hypertension, diabetes mellitus, hyperlipidemia, and atherosclerosis. Data were analyzed using descriptive statistics, independent t-test, analysis of variance (ANOVA), Pearson correlation analysis, and hierarchical multiple regression. Results: Health empowerment had a positive correlation with health literacy and social support. Perceived health status and social activity participation showed significant contribution in explaining health empowerment. Conclusion: This study showed that enhancing perceived health status and social activity participation are vital in an effort to improve health empowerment of the population. Main findings of this study can contribute to developing health empowerment interventions to improve health behavior practices of the older adults.

Key Words: Cardiovascular diseases, Elderly, Empowerment

\section{INTRODUCTION}

\section{Background}

Cardio-cerebrovascular diseases are prevalent chronic diseases occurring in old age, and the mortality rate tends to increase rapidly with age. Cardio-cerebrovascular diseases refer collectively to cerebrovascular diseases such as stroke including cerebral hemorrhage and cerebral infarction, heart diseases such as ischemic heart diseases including myocardial infarction, angina pectoris, and heart failure, and high-risk diseases of cardio-cerebrovascular system such as hypertension, diabetes, hyperlipidemia, and atherosclerosis [1]. Cardio-cerebrovascular diseases account for the highest number of deaths, following malignant neoplasms, and these rankings have remained unchanged over the past decade. It is noteworthy that the mortality rate per 100,000 population from circulatory system diseases is much higher in older adult population, with 130.1 persons in 60 69 age group and 520.9 persons in 70 79 age group compared to 23.4 persons in $40 \sim 49$ age group [2]. Since cardio-cerebrovascular diseases of older adults are accompanied by various neurological impairments and sequelae, functional defects, and medical complications even after successful surgeries and treatments, it is difficult for patients to return to their daily lives, and the socio-economic burden is also quite heavy for patients [3]. Therefore, older adults should manage cardio-cerebrovascular diseases in a proactive way, and the care should be taken to prevent high-risk diseases of cardio-cerebrovascular system, such as hypertension, diabetes, hyperlipidemia, and atherosclerosis, from leading to development of severe cardio-cerebrovascular diseases.

In previous studies, major risk factors of deaths from

주요어: 심뇌혈관계 유발질환, 노인, 건강 임파워먼트, 건강행위

Corresponding author: Kim, GwangSuk

College of Nursing, Yonsei University, 50-1 Yonsei-ro, Seodaemun-gu, Seoul 03772, Korea.

Tel: +82-2-2228-3342, Fax: +82-2-392-5440, E-mail: gskim@yuhs.ac

- 이 논문은 제 1 저자 손효진의 석사학위논문을 수정하여 작성한 것임.

- This article is a revision of the 1st author's master's thesis from University.

Received: Jul 20, 2017 / Revised: Nov 1, 2017 / Accepted: Nov 3, 2017

This is an open access article distributed under the terms of the Creative Commons Attribution Non-Commercial License (http://creativecommons.org/licenses/ by-nc/3.0), which permits unrestricted non-commercial use, distribution, and reproduction in any medium, provided the original work is properly cited. 
cardio-cerebrovascular diseases have been reported to be health behavior factors, such as inadequate nutrition, smoking, drinking, and a lack of exercise [4]. This is based on the fact that health behavior factors can cause pathophysiological risk factors associated with development of cardio-cerebrovascular diseases, such as obesity, hypertension, hyperlipidemia, and diabetes. According to the National Health and Nutrition Examination Survey, the smoking rate and monthly prevalence of heavy episodic drinking of males aged $60 \sim 69$ were $26.1 \%$ and $42.0 \%$, respectively. The practice rate of aerobic physical activity of older adults was less than $50 \%$, and they showed excessively sufficient intake of sodium and insufficient intake of calcium compared to the recommended intake [5]. In order to increase the practice and maintenance rate of health behaviors of older adults with high-risk of cardio-cerebrovascular diseases, we need an approach that motivates older adults to actively participate in their health care [6].

Health empowerment is a combination of the empowerment concept with health behaviors. It is a strategy to manage health problems and control health behaviors by mobilizing personal abilities and social-contextual resources [6]. In other words, health empowerment motivates individuals to recognize their psychosocial attitudes towards health problems, identify problems with their healthcare practices and whether any changes are required, and establish feasible healthcare goals and achieve them [7]. In old age, people are exposed to complex health problems such as increased morbidity rates of various chronic diseases including high-risk diseases of cardio-cerebrovascular system. Health empowerment strategies can lead older adults to make perceived choices regarding their health and act as the main agent of healthcare.

In order for health empowerment to lead to health-related decisions and the implementation of health behaviors, a corresponding high level of health literacy should be balanced with health empowerment. Health literacy is the ability to obtain, understand, and manage health information [8] and it is a major factor in determining health status. As the importance of self-determination in health management is being increased, it is necessary to provide patients with high quality information, and patients need to be equipped with appropriate levels of health literacy and health empowerment [9]. However, research on the relationship between health literacy and health empowerment has been limited, and the results of previous studies were inconsistent.

To improve health empowerment, it is also necessary to provide social-contextual resources in addition to personal abilities such as health literacy. Social support refers to receiving various forms of help through interpersonal relationships such as families, friends and neighbors [10] and it has a direct or indirect effect on health-related quality of life and health status of older adults [11,12]. Social support is also associated with health empowerment as a factor that enhances the self-confidence in personal healthcare and strengthens the ability of the community solving health problems [13,14]. In addition, empowerment of older adults can vary depending on the degree of social activity participation [15]. However, there has been a lack of studies examining social-contextual factors and health empowerment in older adult population.

Previous studies on health empowerment in older adult population have investigated the relationship between empowerment and major variables in older adults living at home [14-17], validated an instrument measuring health empowerment [18], and tested a health empowerment intervention to older adults with chronic diseases [19]. However, there have not been many studies on health empowerment of older adults with high-risk of cardio-cerebrovascular diseases. Therefore, this study aimed to assess the level of health empowerment of older adults with highrisk of cardio-cerebrovascular diseases and to identify factors that explain health empowerment.

\section{Purpose}

The aim of this study is as follows.

- To assess the level of health empowerment of older adults with high-risk of cardio-cerebrovascular diseases.

- To compare the difference of health empowerment according to personal characteristics including health literacy and social-contextual characteristics including social support of older adults with high-risk of cardio-cerebrovascular diseases.

- To identify factors that explain health empowerment of older adults with high-risk of cardio-cerebrovascular diseases.

\section{METHODS}

\section{Study Design}

This study is a descriptive, cross-sectional study to assess the level of health empowerment of older adults living at home and having high-risk diseases of cardio-cerebrovascular system and to identify factors explaining their health empowerment. 


\section{Study sample}

From 25 districts in Seoul city, 2 districts were selected by convenience sampling. The study recruited older adults aged 65 or over who were residing in the 2 districts. The sample was recruited from welfare centers, senior centers, and public health centers. All participants had been diagnosed with at least one of the following diseases for more than 3 months: hypertension, diabetes, hyperlipidemia, and atherosclerosis. The study included those who understood the study purpose, were not cognitively impaired, and voluntarily agreed their participation. The sample size was calculated using the $G^{*}$ Power 3.1.9.2 program. To perform multiple regression analysis the minimum required number of participants was 123 when 11 predictors were set under the significance level .05, effect size .15, and power $80 \%$. Considering a dropout rate of $20 \%$, the target number of participants was 150. A total of 158 participants were recruited. After excluding 7 cases not meeting the selection criteria and 3 cases having missing values, data from 148 participants were used for the final analysis.

\section{Study measures}

\section{1) Health empowerment}

After getting the approval from the developer, the Diabetes Empowerment Scale (DES)[20] was modified and translated to measure health empowerment of older adults with high-risk of cardio-cerebrovascular diseases. DES was originally developed by Anderson and colleagues to measure empowerment of diabetes patients. For example, one item 'I can choose realistic diabetes goals' was modified and translated into 'I can choose realistic goals to manage my disease.' The study researcher, a doctoral student in nursing science, and a doctoral student in English literature independently drafted translations and jointly decided on the final version of each item. A doctoral student in Korean literature and a professor from nursing department reviewed the appropriateness of the translation and complemented the final draft. This measure consists of 3 subscales: managing the psychosocial aspects of diseases (9 items), assessment of dissatisfaction and readiness to change (9 items), and setting and achieving disease management goals (10 items). Each item is on a 5-point scale, and the final score can be obtained by dividing the sum of each item score by the number of items. A higher score indicates a higher level of health empowerment. Reliability was checked by the Spearman's correlation coefficient calculated after a test-retest and Cronbach's $\alpha$. From the 2-week interval test-retest conducted on 10 older adults, the correlation coefficient was .92 $(p<.001)$. Cronbach's $\alpha$ of the original instrument was .96 , and Cronbach's $\alpha$ of the study instrument was .94 .

\section{2) Personal characteristics}

(1) Health literacy

Health literacy was measured by the Short Korean Health Literacy Scale (SKHLS) developed by Lee and Kang [21]. SKHLS consists of 12 items: 5 items in the health-related terms and 7 items in the comprehension and numeracy. Scores range from 0 to 12 , and a higher total score indicates a higher health literacy level. Cronbach's $\alpha$ was .80 when the instrument was developed. Cronbach's $\alpha$ was .87 in this study.

(2) Demographics and health status

Besides health literacy, demographics were collected including age, gender, presence of spouse, type of household, education, occupation, subjective living standard, perceived health status, and type of high-risk diseases of cardio-cerebrovascular system.

\section{3) Social-contextual characteristics}

(1) Social support

Social support was measured by the Korean version of Medical Outcomes Social Support Survey (MOS-SSS). The Rand and Medical Outcomes Study Team (MOS) developed MOS-SSS in 1991, and Lim translated it into Korean [22]. The instrument consists of 20 items: 1 item of structural support and 19 items of functional support. The structural support item asks the number of people who one feels comfortable together and communicates freely. Functional support items have following subscales: tangible support (4 items), affectionate support (3 items), positive social interaction (4 items), and emotional/informational support (8 items). Each item was measured on a 5-point scale. For each subscale, the item scores were summed and converted to a score ranging from 0 to 100, and the mean score was calculated. A higher mean score indicates a higher level of functional support. Cronbach's $\alpha$ of the original instrument was .97, and Cronbach's $\alpha$ of the Korean version was .98. In this study, Cronbach's $\alpha$ was 97.

(2) Social activity and healthcare visit

Besides social support, social-contextual characteristics included health insurance, social activity participation, type of leisure activity, source of daily support, institution for healthcare visit, main reason for healthcare visit, and frequency of healthcare visit. 


\section{Data collection}

The ethical approval for the study was obtained from the Institutional Review Board (IRB) of the College of Nursing at Yonsei University (IRB 2016-0009-2). A preliminary survey was conducted on 5 older adults living in Seoul. Participants of the preliminary survey completed the questionnaire by themselves. For those who need an assistance in completing the questionnaire, an one-on-one interview method was employed. Approximately $30 \mathrm{mi}-$ nutes was spent for participants completing the questionnaire, and there was no such item that participants could not understand or felt awkward. The main survey was conducted at welfare centers, senior centers, and public health centers in 2 districts of Seoul from April to May 2016. Accompanied with a research assistant, data were collected in the same manner as the preliminary survey. Older adults who agreed to participate in the survey were asked whether they had one or more diseases among hypertension, diabetes, hyperlipidemia, and atherosclerosis. To determine their disease state those who answered 'yes' were asked whether the disease was diagnosed by a doctor. Older adults who met all the inclusion criteria participated in the survey after being informed about the study purpose, estimated time for completing the questionnaire, and guaranteed voluntary participation.

\section{Data analysis}

The data were analyzed using the SPSS 21.0 program as follows:

- Health empowerment, personal characteristics including health literacy, and social-contextual characteristics including social support were analyzed by descriptive statistics (frequency, proportion, mean, and standard deviation [SD]).

- The difference of health empowerment according to personal characteristics and social-contextual characteristics by independent $\mathrm{t}$-test and analysis of variance (ANOVA).

- Correlations between health empowerment and main variables were examined by Pearson correlation analysis.

- Factors explaining health empowerment were identified by hierarchical multiple regression analysis.

\section{RESULTS}

\section{Participant Characteristics and Health Empower- ment}

\section{1) Personal characteristics and social-contextual character-} istics

Personal characteristics and social-contextual characteristics are shown in Table 1 . The mean age was $75.6 \pm$ 6.18 years, and participants aged 75 to 84 years accounted for $48.0 \%$, which was the largest. More than half of participants $(66.2 \%)$ were female, and $57.4 \%$ had no spouse. Participants living with their families were $60.8 \%$, and $39.2 \%$ were living alone. About half of participants (51.4\%) had elementary school education or below. The majority of participants $(77.0 \%)$ reported that they were not employed. For the subjective living standard, $52.7 \%$ answered as average, $41.9 \%$ answered as poor, and $5.4 \%$ answered as wealthy. For the perceived health status, $42.6 \%$ answered as not healthy, $31.7 \%$ answered as fair, and $25.7 \%$ answered as healthy. The most common type of high-risk diseases of cardio-cerebrovascular system was hypertension $(85.1 \%)$, followed by hyperlipidemia $(31.1 \%)$, diabetes $(24.3 \%)$ and atherosclerosis $(2.7 \%)$.

The mean score of health literacy was $7.51 \pm 3.46$ out of 12. The mean score of the subscale 'health related terms' was $3.72 \pm 1.54$ out of 5 , and the mean score of the subscale 'comprehension and numeracy' was $3.79 \pm 2.22$ out of 7 .

The majority of participants (77.7\%) were national health insurance subscribers, $14.2 \%$ were medicaid recipients, and $8.1 \%$ did not exactly know about their health insurance. For the social activity participation, $50.7 \%$ answered as average, $26.3 \%$ answered as low, and $23.0 \%$ answered as good. For the type of leisure activity, $62.2 \%$ answered for group activities, $22.3 \%$ answered for individual activities, and $15.5 \%$ answered for none. Sources of daily support were spouse/children (58.8\%), certain organizations (23.6\%), friends/neighbors (9.5\%), and none (8.1\%). For healthcare visit, more than half of participants (55.4\%) mainly visited local hospitals/clinics, $31.1 \%$ mainly visited public health centers, and $13.5 \%$ mainly visited tertiary/general hospitals. Main reasons for healthcare visit were drug prescription (73.0\%), health check-up (20.3\%), and treatments/procedures (6.7\%). About $60 \%$ of participants did healthcare visit more frequently than once every 2 months.

For the social support, the mean number of structural support was $4.24 \pm 4.46$ persons, ranging from 0 to 30 . The mean score of functional support was $56.41 \pm 25.16$ out of 100 , and the mean score of each subscale is as follows: tangible support $56.93 \pm 28.38$, affectionate support $57.71 \pm$ 28.66 , positive social interaction $55.70 \pm 28.38$, and emotional/informational support 55.28 \pm 24.37 .

\section{2) Health empowerment}

The result of health empowerment is presented in Table 2 . 
Table 1. Personal and Social-Contextual Characteristics

\begin{tabular}{|c|c|c|c|}
\hline Variables & Categories & $\mathrm{n}(\%)$ or $\mathrm{M} \pm \mathrm{SD}$ & Range \\
\hline Age (year) & $\begin{array}{l}65 \sim<75 \\
75 \sim<85 \\
\geq 85\end{array}$ & $\begin{array}{c}75.6 \pm 6.18 \\
63(42.5) \\
71(48.0) \\
14(9.5)\end{array}$ & $65 \sim 90$ \\
\hline Gender & $\begin{array}{l}\text { Male } \\
\text { Female }\end{array}$ & $\begin{array}{l}50(33.8) \\
98(66.2)\end{array}$ & \\
\hline Type of household & $\begin{array}{l}\text { With family } \\
\text { Alone }\end{array}$ & $\begin{array}{l}90(60.8) \\
58(39.2)\end{array}$ & \\
\hline Education & $\begin{array}{l}\text { None } \\
\text { Elementary school } \\
\text { Middle school } \\
\geq \text { High school }\end{array}$ & $\begin{array}{l}21(14.2) \\
55(37.2) \\
24(16.2) \\
48(32.4)\end{array}$ & \\
\hline Living standard & $\begin{array}{l}\text { Poor } \\
\text { Average } \\
\text { Wealthy }\end{array}$ & $\begin{array}{c}62(41.9) \\
78(52.7) \\
8(5.4)\end{array}$ & \\
\hline Perceived health status & $\begin{array}{l}\text { Not healthy } \\
\text { Fair } \\
\text { Healthy }\end{array}$ & $\begin{array}{l}63(42.6) \\
47(31.7) \\
38(25.7)\end{array}$ & \\
\hline Type of high risk diseases $^{\dagger}$ & $\begin{array}{l}\text { Hypertension } \\
\text { Hyperlipidemia } \\
\text { Diabetes mellitus } \\
\text { Arteriosclerosis }\end{array}$ & $\begin{array}{c}126(85.1) \\
46(31.1) \\
36(24.3) \\
4(2.7)\end{array}$ & \\
\hline Health literacy (total score) & $\begin{array}{l}\text { Health-related terms } \\
\text { Comprehension and numeracy }\end{array}$ & $\begin{array}{l}7.51 \pm 3.46 \\
3.72 \pm 1.54 \\
3.79 \pm 2.22\end{array}$ & $\begin{array}{l}0 \sim 12 \\
0 \sim 5 \\
0 \sim 7\end{array}$ \\
\hline Social activity participation & $\begin{array}{l}\text { Low } \\
\text { Average } \\
\text { Good }\end{array}$ & $\begin{array}{l}39(26.3) \\
75(50.7) \\
34(23.0)\end{array}$ & \\
\hline Type of leisure activity & $\begin{array}{l}\text { Group } \\
\text { Individual } \\
\text { None }\end{array}$ & $\begin{array}{l}92(62.2) \\
33(22.3) \\
23(15.5)\end{array}$ & \\
\hline Source of daily support & $\begin{array}{l}\text { Spouse/children } \\
\text { Organizations } \\
\text { Friends/neighbors } \\
\text { None }\end{array}$ & $\begin{array}{l}87(58.8) \\
35(23.6) \\
14(9.5) \\
12(8.1)\end{array}$ & \\
\hline Institution for healthcare visit & $\begin{array}{l}\text { Local hospitals/clinics } \\
\text { Public health centers } \\
\text { Tertiary/general hospitals }\end{array}$ & $\begin{array}{l}82(55.4) \\
46(31.1) \\
20(13.5)\end{array}$ & \\
\hline Main reason for healthcare visit & $\begin{array}{l}\text { Drug prescription } \\
\text { Health check-up } \\
\text { Treatment/procedure }\end{array}$ & $\begin{array}{c}108(73.0) \\
30(20.3) \\
10(6.7)\end{array}$ & \\
\hline Frequency of healthcare visit & $\begin{array}{l}>\text { Bimonthly } \\
\text { Bimonthly Quarterly } \\
<\text { Quarterly }\end{array}$ & $\begin{array}{l}89(60.1) \\
49(33.1) \\
10(6.8)\end{array}$ & \\
\hline \multicolumn{4}{|l|}{ Social support } \\
\hline Structural support (person) & & $4.24 \pm 4.46$ & $0 \sim 30$ \\
\hline Functional support (total score) & $\begin{array}{l}\text { Tangible } \\
\text { Affectionate } \\
\text { Positive social } \\
\text { Emotional/information support }\end{array}$ & $\begin{array}{l}56.41 \pm 25.16 \\
56.93 \pm 28.38 \\
57.71 \pm 28.66 \\
55.70 \pm 28.38 \\
55.28 \pm 24.37\end{array}$ & $\begin{array}{l}0 \sim 100 \\
0 \sim 100 \\
0 \sim 100 \\
0 \sim 100 \\
0 \sim 100\end{array}$ \\
\hline
\end{tabular}

${ }^{\dagger}$ Plural response. 
The mean score of health empowerment was $3.42 \pm 0.67$ out of 5 , ranging from 1 to 5 . The subscale 'managing the psychosocial aspects of diseases' had the highest mean score of $3.56 \pm 0.82$, and the mean score of the subscale 'assessment of dissatisfaction and readiness to change' was $3.30 \pm 0.60$, and the mean score of the subscale 'setting and achieving disease management goals' was $3.40 \pm 0.84$. The mean score of each subscale ranged from 1 to 5 .

\section{Health empowerment according to participant characteristics}

Table 3 shows the participant characteristics that had significant differences in health empowerment. The personal characteristics were age, presence of spouse, type of household, education, subjective living standard, and perceived health status. Health empowerment was significantly higher in 65 74 age group than in 75 84 age group ( $\mathrm{F}=4.06, p=.019)$, and health empowerment was significantly higher in participants with spouse than participants without spouse $(\mathrm{t}=2.40, p=.018)$. Participants living with family showed higher health empowerment than those living alone $(t=-2.35, p=.020)$. For the education, participants with high school education or above showed significantly higher health empowerment than those with elementary school education or below $(\mathrm{F}=4.10, p=.008)$.

Table 2. Distribution of Health Empowerment

$(N=148)$

\begin{tabular}{lcccc}
\hline Variable & Items & M SD & Range \\
\hline Health empowerment & 28 & $3.42 \pm 0.67$ & $1 \sim 5$ & $1 \sim 5$ \\
$\quad$ Managing the psychosocial aspects of diseases & 9 & $3.56 \pm 0.82$ & $1 \sim 5$ \\
Assessment of dissatisfaction and readiness to change & 9 & $3.30 \pm 0.60$ & $3.40 \pm 0.84$ & $1 \sim 5$ \\
\hline Setting and achieving disease management goals & 10 & & $1 \sim 2$ \\
\hline
\end{tabular}

Table 3. Health Empowerment by Personal and Social-Contextual Characteristics

\begin{tabular}{|c|c|c|c|c|}
\hline Variables & Categories & $\mathrm{M} \pm \mathrm{SD}$ & $\begin{array}{c}\mathrm{t} \text { of } \mathrm{F} \\
\text { (post-hoc) }\end{array}$ & $p$ \\
\hline Age (year) & $\begin{array}{l}65 \sim<75^{\mathrm{a}} \\
75 \sim<85^{\mathrm{b}} \\
\geq 85^{\mathrm{c}}\end{array}$ & $\begin{array}{l}3.60 \pm 0.54 \\
3.29 \pm 0.72 \\
3.26 \pm 0.79\end{array}$ & $\begin{array}{c}4.06 \\
(a>b)^{\dagger}\end{array}$ & .019 \\
\hline Spouse & $\begin{array}{l}\text { No } \\
\text { Yes }\end{array}$ & $\begin{array}{l}3.31 \pm 0.68 \\
3.57 \pm 0.63\end{array}$ & 2.40 & .018 \\
\hline Type of household & $\begin{array}{l}\text { With family } \\
\text { Alone }\end{array}$ & $\begin{array}{l}3.52 \pm 0.62 \\
3.26 \pm 0.71\end{array}$ & -2.35 & .020 \\
\hline Education & $\begin{array}{l}\text { None }^{\mathrm{a}} \\
\text { Elementary school }^{\mathrm{b}} \\
\text { Middle school }^{\mathrm{c}} \\
\geq \text { High school }^{\mathrm{d}}\end{array}$ & $\begin{array}{l}3.28 \pm 0.78 \\
3.25 \pm 0.67 \\
3.42 \pm 0.69 \\
3.68 \pm 0.54\end{array}$ & $\begin{array}{c}4.10 \\
(\mathrm{~b}<\mathrm{d})^{\dagger}\end{array}$ & .008 \\
\hline Living standard & $\begin{array}{l}\text { Poor }^{\mathrm{a}} \\
\text { Average }^{\mathrm{b}} \\
\text { Wealthy }^{\mathrm{c}}\end{array}$ & $\begin{array}{l}3.25 \pm 0.64 \\
3.53 \pm 0.67 \\
3.67 \pm 0.62\end{array}$ & $\begin{array}{c}3.82 \\
(\mathrm{a}<\mathrm{b})^{\dagger}\end{array}$ & .024 \\
\hline Perceived health status & $\begin{array}{l}\text { Not healthy } \\
\text { Fair }^{\mathrm{b}} \\
\text { Healthy }^{\mathrm{c}}\end{array}$ & $\begin{array}{l}3.22 \pm 0.69 \\
3.46 \pm 0.59 \\
3.69 \pm 0.64\end{array}$ & $\begin{array}{c}6.47 \\
(\mathrm{a}<\mathrm{c})^{\dagger}\end{array}$ & .002 \\
\hline Social activity participation & $\begin{array}{l}\text { Low }^{a} \\
\text { Average }^{b} \\
\text { Good }^{\mathrm{c}}\end{array}$ & $\begin{array}{l}2.96 \pm 0.64 \\
3.56 \pm 0.61 \\
3.64 \pm 0.58\end{array}$ & $\begin{array}{c}14.92 \\
(\mathrm{a}<\mathrm{b}, \mathrm{c})^{\dagger}\end{array}$ & $<.001$ \\
\hline Frequency of healthcare visit & $\begin{array}{l}>\text { Bimonthly }^{\mathrm{a}} \\
{\text { Bimonthly } \text { Quarterly }^{\mathrm{b}}}_{\text {< }^{\mathrm{C}} \text { Quarterly }^{\mathrm{c}}}\end{array}$ & $\begin{array}{l}3.29 \pm 0.69 \\
3.65 \pm 0.60 \\
3.48 \pm 0.54\end{array}$ & $\begin{array}{c}4.79 \\
(\mathrm{a}<\mathrm{b})^{\dagger}\end{array}$ & .010 \\
\hline
\end{tabular}

${ }^{\dagger}$ Dunnett T3; ${ }^{\dagger}$ Scheffé test. 
Participants who answered their subjective living standard as average had significantly higher health empowerment than those who answered it as poor $(\mathrm{F}=3.82, p=.024)$. Participants who answered the perceived health status as healthy showed significantly higher health empowerment than those who answered it as not healthy $(\mathrm{F}=6.47, p=$ .002).

From the social-contextual characteristics, there were significant differences in health empowerment according to social activity participation and frequency of healthcare visit. Participants with an average or good level of social activity participation showed significantly higher health empowerment than those with a low level of social activity participation $(\mathrm{F}=14.92, p<.001)$. For the frequency of healthcare visit, participants who did healthcare visit once every 2 months or quarterly showed significantly higher health empowerment than participants who did healthcare visit more frequently than once every 2 months $(\mathrm{F}=$ $4.79, p=.010)$.

\section{Correlations between Health Empowerment, Health Literacy, and Social Support}

Table 4 shows the correlations between health empowerment, health literacy, and social support. Health literacy was positively correlated with health empowerment $(\mathrm{r}=.21$, $p=.012$ ). Two subscales of social support were significantly correlated with health empowerment. Structural support had a positive correlation with health empowerment $(\mathrm{r}=$ $.17, p=.043$ ), and functional support also had a positive correlation with health empowerment $(\mathrm{r}=.29, p<.001)$.

\section{Factors Explaining Health Empowerment}

In order to identify factors that explain health empowerment, a hierarchical multiple regression analysis was performed and the results are shown in Table 5. Personal characteristics that showed significant differences in health empowerment were entered as independent variables: age, presence of spouse, type of household, education, subjective living standard, and perceived health status. Along with the personal characteristics, social-contextual characteristics that showed significant differences in health empowerment were entered as independent variables: social activity participation and frequency of healthcare visit. Health literacy and social support were also included as independent variables since both were significantly correlated with health empowerment.

The following assumptions of multiple regression analysis were satisfied: linearity, normality, independence, and homoscedasticity. The tolerance was .22 .86 and the variance inflation factor (VIF) was 1.16 4.61, indicating that there was no issue of multicollinearity.

Model 1, which included the personal characteristics, explained $11 \%$ of health empowerment $(\mathrm{F}=2.53, p=.005)$. Healthy group of perceived health status was identified as a significant factor explaining health empowerment $(\beta=$ $.24, p=.010)$. Model 2, which added the social-contextual characteristics, explained $22 \%$ of health empowerment ( $F=3.27, p<.001)$. In Model 2, significant factors explaining health empowerment were healthy group of perceived health status $(\beta=.19, p=.041)$, the group with average level of social activity participation $(\beta=.36, p<.001)$, and the group with high level of social activity participation $(\beta=$ $.38, p<.001)$.

\section{DISCUSSION}

This study was conducted to assess the level of health empowerment of older adults aged 65 years or older living at home and had high-risk diseases of cardio-cerebrovascular system, and to identify factors explaining health empowerment.

In this study, health empowerment was measured by a modified and translated version of DES [20] that was originally developed to measure empowerment of diabetic patients. The mean score was 3.42 out of 5 . A prior study of older adults aged 60 years or older measured health empowerment using a modified and translated version of DES-Short Form (DES-SF)[23], which is a shorter version of DES, and the mean score of health empowerment was 3.51[18]. Another previous study measured health empowerment of older adults with chronic diseases aged 65 years or older using DES-SF, and the mean score of the experimental group was 3.56 and the mean score of the control group was 3.80, at pre-intervention [19]. It is difficult to simply compare the two prior studies with this study because those studies did not measure health empowerment with the same instrument as this study, and there are differences in participant characteristics. However, 89.7\% participants of the first study had more than one chronic disease, and participants of the second study were older adults with chronic diseases. Therefore, if high-risk diseases of cardio-cerebrovascular system were classified as chronic diseases, health empowerment of this study can be considered to be similar or slightly lower than those reported in the two previous studies. In another intervention study that measured empowerment of hypertensive patients visiting a public health center using a modified and translated version of DES-SF, the mean score of the ex- 
perimental group was 3.55 and the mean score of the control group was 3.40, at pre-intervention. The mean age of the study participants was 64.58 years. Considering that the mean age of participants in this study was 75.60 years and the majority $(85.1 \%)$ had hypertension, health empowerment in this study is considered to be similar to that of the previous study.

Factors that explain health empowerment were per-

Table 4. Correlations between Health Empowerment, Health Literacy, and Social Support

$(N=148)$

\begin{tabular}{lcccc}
\hline Variables & HE (r) & HL (r) & SS (r) & FS (r) \\
\hline Health empowerment (HE) & & & & \\
Health literacy (HL) & $.21^{*}$ & & & \\
Structural support (SS) & $.17^{*}$ & $.25^{* *}$ & & \\
Functional support (FS) & $.29^{* *}$ & $.36^{* *}$ & $.43^{* *}$ & \\
\hline
\end{tabular}

${ }^{*} p<.05,{ }^{* *} p<.01$. ceived health status and social activity participation. Perceived health status is a self-assessment of health status. The concept of perceived health status, which is often measured as the health performance index of patients, has recently been treated as the perception of one's own health and has been included as a factor to explain empowerment for healthcare. Rohrer et al.[25] also reported a significant difference in empowerment according to the patients' perceived health status. In this study, participants who answered their health as healthy showed significantly higher health empowerment than those who answered their health as not healthy. In order to increase health empowerment of older adults with high-risk of cardio-cerebrovascular diseases, it would be necessary to develop the interventions that improve their perceived health status. Healthcare providers also need to monitor perceived health status as a major indicator of healthcare along with objective clinical data.

Social activity participation is the subjective judgment

Table 5. Hierarchical Multiple Regression for Health Empowerment

$(N=148)$

\begin{tabular}{|c|c|c|c|c|c|c|c|}
\hline \multirow{2}{*}{ Variables } & \multirow{2}{*}{ Categories } & \multicolumn{3}{|c|}{ Model 1} & \multicolumn{3}{|c|}{ Model 2} \\
\hline & & $\beta$ & SE & $\mathrm{t}$ & $\beta$ & SE & $\mathrm{t}$ \\
\hline \multirow{2}{*}{$\begin{array}{l}\text { Age (year) } \\
\text { (Ref: } 65 \sim<75)\end{array}$} & $75 \sim<85$ & .01 & 0.20 & 0.07 & -.02 & 0.19 & -0.11 \\
\hline & $\geq 85$ & .08 & 0.22 & 0.47 & .01 & 0.21 & 0.08 \\
\hline $\begin{array}{l}\text { Spouse } \\
\text { (Ref: Yes) }\end{array}$ & No & -.08 & 0.15 & -0.66 & -.06 & 0.15 & -0.54 \\
\hline $\begin{array}{l}\text { Type of household } \\
\text { (Ref: Alone) }\end{array}$ & With family & .07 & 0.15 & 0.69 & .01 & 0.15 & 0.13 \\
\hline \multirow{3}{*}{$\begin{array}{l}\text { Education } \\
\text { (Ref: None) }\end{array}$} & Elementary school & -.12 & 0.18 & -0.91 & -.09 & 0.18 & -0.73 \\
\hline & Middle school & -.06 & 0.23 & -0.52 & -.09 & 0.22 & -0.77 \\
\hline & $\geq$ High school & .04 & 0.22 & 0.26 & .03 & 0.22 & 0.20 \\
\hline \multirow{2}{*}{$\begin{array}{l}\text { Living standard } \\
\text { (Ref: Poor) }\end{array}$} & Average & .13 & 0.11 & 1.50 & .04 & 0.11 & 0.42 \\
\hline & Wealthy & .09 & 0.25 & 1.03 & .07 & 0.24 & 0.85 \\
\hline \multirow{2}{*}{$\begin{array}{l}\text { Perceived health status } \\
\text { (Ref: Not healthy) }\end{array}$} & Fair & .13 & 0.13 & 1.48 & .11 & 0.12 & 1.23 \\
\hline & Healthy & .24 & 0.14 & $2.61^{*}$ & .19 & 0.14 & $2.07^{*}$ \\
\hline \multicolumn{2}{|l|}{ Health literacy } & .06 & 0.02 & 0.57 & .07 & 0.02 & 0.73 \\
\hline \multirow{2}{*}{$\begin{array}{l}\text { Social activity participation } \\
\text { (Ref: Low) }\end{array}$} & Average & & & & .36 & 0.13 & $3.63^{* *}$ \\
\hline & Good & & & & .38 & 0.15 & $3.98^{* *}$ \\
\hline \multirow{2}{*}{$\begin{array}{l}\text { Frequency of healthcare visit } \\
\text { (Ref: > Bimonthly) }\end{array}$} & Bimonthly Quarterly & & & & .14 & 0.12 & 1.65 \\
\hline & $<$ Quarterly & & & & -.02 & 0.22 & -0.27 \\
\hline \multicolumn{2}{|l|}{ Structural support } & & & & -.09 & 0.01 & -0.94 \\
\hline \multirow[t]{4}{*}{ Functional support } & & & & & .10 & 0.00 & 0.93 \\
\hline & & \multicolumn{3}{|c|}{$\mathrm{R}^{2}=.18$} & \multicolumn{3}{|c|}{$\mathrm{R}^{2}=.31$} \\
\hline & & \multicolumn{3}{|c|}{ Adjusted $\mathrm{R}^{2}=.11$} & \multicolumn{3}{|c|}{ Adjusted $\mathrm{R}^{2}=.22$} \\
\hline & & \multicolumn{3}{|c|}{$\mathrm{F}=2.53, p=.005$} & \multicolumn{3}{|c|}{$\mathrm{F}=3.27, p<.001$} \\
\hline
\end{tabular}

Ref=reference group; ${ }^{*} p<.05,{ }^{* *} p<.01$. 
on the extent to which individuals participate in "activities with certain rules or forms related to interactions with others"[26]. In this study, social activity participation is defined as including economic activities in which profit is generated and non-profit activities such as community organizational activities and group activities. In this study, participants with an average or good level of social activity participation showed significantly higher health empowerment than those with a low level of social activity participation. In Lee [27], empowerment of older adults with a upper level of social activity participation was higher than those with a lower level of social activity participation. Ha et al.[15] explained that older adults who have less restrictions on social activities may have different levels of empowerment because they have more opportunities to make social connections by using their resources appropriately. Older adults are more likely to suffer from chronic diseases and their social activity participation tends to be decreased. Therefore, it is necessary to establish plans to promote older adults' social activity participation so that they will not be isolated from society and neglected in vulnerable health conditions.

Among the personal characteristics, in addition to perceived health status, variables such as age, presence of spouse, type of household, education, and subjective living standard showed significant differences in health empowerment, but these variables did not explain health empowerment significantly. Previous studies investigating health empowerment of older adults living at home showed the difference in empowerment according to age, presence of spouse, type of household, and education [15-17]. However, these previous studies only compared the difference in empowerment according to participant characteristics, and did not attempt to identify factors that explain empowerment by regression analysis. Therefore, it is limited to compare previous studies and this study to discuss why the personal characteristics, which had significant differences in health empowerment, were not identified as significant factors from the hierarchical multiple regression analysis. In order to find out whether the personal characteristics are factors explaining health empowerment, further research should be conducted that use regression analysis and structural equation modeling methods.

Social-contextual characteristic that produced significant differences in health empowerment besides social activity participation was frequency of healthcare visits. In this study, $60.1 \%$ participants reported that they did healthcare visit more frequently than once every 2 months, and their health empowerment was lower than those who did healthcare visit less frequently. However, frequency of healthcare visit was not a factor explaining health empowerment significantly. This may be the result of the association between frequency of healthcare visit and perceived health status. In fact, when a cross-tabulation analysis was performed with two variables, $71.4 \%$ of those who answered their perceived health status as not healthy did healthcare visit more frequently than once every 2 months $(p<.001)$. Further research is needed to clarify the relationship between these two variables.

In this study, health literacy showed a significantly positive correlation with health empowerment. There has been a lack of research that explores both health literacy and health empowerment in older adults with high-risk of cardio-cerebrovascular diseases, and studies conducted with other populations have reported inconsistent results about the relationship between the two concepts. Although health literacy was not a significant factor explaining health empowerment in this study, it is possible that health literacy indirectly explained health empowerment through perceived health status. Previous research reported that health literacy is significantly correlated with perceived health status, and furthermore, it was found to be a factor explaining perceived health status [28]. Thus, it is recommended to conduct further research to verify the direct and indirect pathways that explain health empowerment.

In this study, social support showed a significant correlation with health empowerment. Shearer [14] found that social support was a significant predictor of women's health empowerment, and Shearer and Fleury [13] suggested that social support helps older women to be in harmony with changes in the aging process, and thereby enhances their health empowerment. However, in this study, social support was not a factor explaining health empowerment significantly. Yet, it is possible that social support explains health empowerment through perceived health status and social activity participation. In previous studies, social support significantly explained perceived health status of older adults [12], and was identified as a significant factor explaining social activity participation of older adults with chronic diseases [29]. Therefore, in future studies, it is suggested to verify the path through which social support directly or indirectly explains health empowerment.

Since participants in this study were selected by convenience sampling from 2 districts of Seoul, there is a limitation on generalization of the study results. It is also difficult to confirm the direct or indirect paths of factors explaining health empowerment due to the nature of research design. Nevertheless, this study can be considered 
meaningful, given that there have not been many empirical studies of health empowerment of older adults with high-risk of cardio-cerebrovascular diseases. In addition, the study results can be used as important data when designing and conducting future intervention studies based on health empowerment.

\section{CONCLUSION}

The purpose of this study was to investigate the level of health empowerment and factors explaining health empowerment of older adults with high-risk of cardio-cerebrovascular diseases who need to perform health-promoting behaviors continuously. Among personal characteristics, health empowerment was significantly different according to age, presence of spouse, type of household, education, subjective living standard, and perceived health status. Among social-contextual characteristics, health empowerment was significantly different according to social activity participation and frequency of healthcare visit. Health literacy, social support, and health empowerment were all significantly correlated. As a result of hierarchical multiple regression analysis, the variables significantly explaining health empowerment were perceived health status and social activity participation. The main results of this study can be used for developing programs to improve health empowerment and promote health behavior practices of older adults with high-risk of cardio-cerebrovascular diseases.

Based on the study results, there are suggestions for future research and nursing practice in order to improve health empowerment of older adults with high-risk of cardio-cerebrovascular diseases.

First, since the study participants were selected by convenience sampling from 2 districts of Seoul, it is limit to generalize the study results. Therefore, it is necessary to conduct repeated research by expanding the regions.

Second, in this study, it was difficult to identify the direct or indirect paths of factors that explain health empowerment. Further research is needed to identify the path leading to health empowerment using different research designs and analysis methods.

Third, this study measured health empowerment with the instrument modified and translated DES into Korean. During the data collection process, there were opinions that some items did not written intuitively and it took some time to understand them. Therefore, it is suggested to develop a health empowerment measurement instrument reflecting the literacy level and cultural characteristics of older adults in Korea.
Fourth, there has been a lack of empirical research on health empowerment of older adults in Korea. Thus, it is recommended to conduct research on the development of programs based on health empowerment that can be applied in practice and verification of its effectiveness.

\section{REFERENCES}

1. Ministry of Health and Welfare. 2011 2015 comprehensive countermeasures for cardio-cerebrovascular diseases [Internet]. Seoul: Ministry of Health and Welfare. 2011 [cited 2017 September 4]. Available from:

http://www.mohw.go.kr/front_new/gm/sgm0601vw.jsp?P AR_MENU_ID=13\&MENU_ID=1304020301\&page $=4 \& C O N T$ SEQ=293395

2. Statistics Korea. 2015 cause of death statistics [Internet]. Daejeon: Statistics Korea. 2016 [cited 2017 September 4]. Available from: http://kostat.go.kr/portal/korea/kor_nw/2/6/2/index.boa rd?bmode $=$ read\&bSeq $=\& a S e q=356345 \&$ pageNo $=1 \&$ row $\mathrm{Nu}$ $\mathrm{m}=10 \&$ navCount $=10 \&$ currPg=\&sTarget=title\&sTxt=

3. Hong SM, Byeon HW, Kim JS, Mun SH. Development of risk prediction model for cardiovascular disease among community-dwelling elderly. Asia-pacific Journal of Multimedia Services Convergent with Art, Humanities, and Sociology. 2015; 5(1):37-46. https://doi.org/10.14257/AJMAHS.2015.02.02

4. Kang HJ, Kwon SM. Regional disparity of cardiovascular mortality and its determinants. Health Policy and Management. 2016;26(1):12-23. https://doi.org/10.4332/KJHPA.2016.26.1.12

5. Korea Centers for Disease Control \& Prevention. 2015 health behavior and chronic disease statistics [Internet]. Cheongju: Korea Centers for Disease Control \& Prevention. 2016 [cited 2017 September 4]. Available from:

http://cdc.go.kr/CDC/contents/CdcKrContentView.jsp?cid =60949\&menuIds=HOME001-MNU1130-MNU1639-MNU17 49-MNU1761

6. Shearer NB. Health empowerment theory as a guide for practice. Geriatric Nursing. 2009;30(2):4-10. https://doi.org/10.1016/j.gerinurse.2009.02.003

7. Feste C, Anderson RM. Empowerment: From philosophy to practice. Patient Education and Counseling. 1995;26(1-3):139144. https://doi.org/10.1016/0738-3991(95)00730-N

8. Institute of Medicine. Health literacy: A prescription to end confusion. Washington, DC: National Academics Press; 2004. $345 \mathrm{p}$.

9. Simoes E, Wallwiener D, Kusicka H, Brucker S. Health literacy requires empowerment - Results of an analysis of patient needs and the demand for qualification over a 10-year period. Geburtshilfe und Frauenheikunde. 2013;73(10):1023-1027. https://doi.org/10.1055/s-0033-1350982

10. Cohen S, Hoberman HM. Positive events and social support as 
buffers life change stress. Journal of Applied Social Psychology. 1983;13(2):99-125.

11. Lee HK, Cho SH, Kim JH, Kim YK, Choo HI. Influence of self efficacy, social support and sense of community on health-related quality of life for middle-aged and elderly residents living in a rural community. 2014;44(6);608-616. https:// doi.org/10.4040/jkan.2014.44.6.608

12. Kang YH, Kim MY, Lee GJ, Jung DY, Ma RW. A study of social support, loneliness, sleep quality, and perceived health status among community-dwelling older adults. Journal of Korean Public Health Nursing. 2012;26(2):303-313. https:// doi.org/10.5932/JKPHN.2012.26.2.303

13. Shearer N, Fleury J. Social support promoting health in older women. Journal of Women and Aging. 2006;18(4):3-17. https://doi.org/10.1300/J074v18n04_02

14. Shearer NBC. Facilitators of health empowerment in women [dissertation]. [Tucson]: The University of Arizona; 2000. 144 p.

15. Ha JY, Yun OJ, Ahn YM. Relationship between empowerment and falls efficacy in community-dwelling older adults. Journal of Korean Gerontological Nursing. 2010;12(3):191-199.

16. Moon MJ. Correlational study of IADL, self-esteem, empowerment of elderly people living at home. Journal of the Korean Academy of Fundamentals of Nursing. 2005;12(3):382-388.

17. Moon MJ. A study on the empowerment, health behavior and life satisfaction in the elderly home residents according to living situations. Journal of Muscle and Joint Health. 2006;13(2): 94-107.

18. Park CR, Park YH. Validity and reliability of Korean version of Health Empowerment Scale (K-HES) for older adults. Asian Nursing Research. 2013;7(3):142-148. https://doi.org/10.1016/j.anr.2013.07.004

19. Park CR, Song MS, Cho BL, Lim JY, Song W, Chang HK, et al. Effects of a multi-disciplinary approached, empowerment theory based self-management intervention in older adults with chronic illness. Journal of Korean Academy of Nursing. 2015; 45(2):192-201. https://doi.org/10.4040/jkan.2015.45.2.192

20. Anderson RM, Funnell MM, Fitzgerald JT, Marrero DG. The diabetes empowerment scale: A measure of psychosocial self- efficacy. Diabetes Care. 2000;23(6):739-743.

21. Lee TW, Kang SJ. Development of the short form of the Korean health literacy scale for the elderly. Research in Nursing and Health. 2013;36(5):524-534.

https://doi.org/10.1002/nur.21556

22. Lim MK. Relationships between social support and health among low income groups in urban area [master's thesis]. [Seoul]: Seoul National University; 2002. 88 p.

23. Anderson RM, Fitzgerald JT, Gruppen LD, Funnell MM, Oh MS. The diabetes empowerment scale-short form (DES-SF). Diabetes Care. 2003;26(5):1641-1642.

24. Chang AK, Fritschi C, Kim MJ. Nurse-led empowerment strategies for hypertensive patients with metabolic syndrome. Contemporary Nurse. 2012;42(1):118-128.

https://doi.org/10.5172/conu.2012.42.1.118

25. Rohrer JE, Wilshusen L, Adamson SC, Merry S. Patient-centeredness, self-rated health, and patient empowerment: Should providers spend more time communicating with their patients? Journal of Evaluation in Clinical Practice. 2008;14(4):548-551. https://doi.org/10.1111/j.1365-2753.2007.00914.x

26. Lee SJ, Chung KH, Lee YK, Yoo SH. Social participation of Korean older persons: Policy implications [Internet]. Seoul: Korea Institute for Health and Social Affairs. 2007 [cited 2017 September 4]. Available from:

http://repository.kihasa.re.kr:8080/bitstream/201002/504/1 /\%EC\%97\%B0\%EA\%B5\%AC-07-19-8.pdf

27. Lee $\mathrm{YH}$. A study on the effect of social participation of the elderly on their empowerment. Journal of Community Welfare. 2003;12:111-129.

28. Kim SH, Lee EJ. The influence of functional literacy on perceived health status in Korean older adults. Journal of Korean Academy of Nursing. 2008;38(2):195-203. https://doi.org/10.4040/jkan.2008.38.2.195

29. Hand C, Law M, McColl MA, Hanna S, Elliott S. An examination of social support influences on participation for older adults with chronic health conditions. Disability and Rehabilitation. 2014;36(17):1439-1444. https://doi.org/10.3109/09638288.2013.845258 